\title{
AS MULHERES ROMANAS E BRETÃS DA BRITANNIA
}

Tais Pagoto Bélo ${ }^{1}$

\begin{abstract}
Resumo
A proposta deste artigo é refletir sobre a mulher na sociedade antiga, em especial na Britannia. O trabalho engloba romanas e bretãs que compuseram diferentes costumes, que se entremearam, que ali viveram e que foram, de alguma forma, evidenciadas por vestígios escritos e/ou materiais.

Este não era um grupo homogêneo, ou seja, tanto para a população que ali já havia se alojado quanto para a que veio depois, deveria existir uma grande variedade de ideias a respeito do status dessas mulheres e do modo como elas deveriam conduzir suas vidas.

Materiais sobre romanas e bretãs já foram encontrados de maneira epigráfica em altares, lápides e sepultamentos. Contudo, este trabalho compara essas primeiras fontes com a obra de Tácito, Anais, uma vez que esse autor parece sempre colocar as mulheres com características pejorativas, muito diferentes das palavras carinhosas e amorosas dadas a elas nesses locais de óbito.
\end{abstract}

\section{Palavras-chave}

Romanas; bretãs; mulheres.

\footnotetext{
1 Pós-doutoranda, CNPq, Universidade Estadual de Campinas, Campinas, Brasil. Email: taispbelo@gmail.com
} 


\begin{abstract}
The purpose of this article is to reflect on women from the ancient society and their studies, especially from Britannia. This work is made up of Romans and Britons women, who composed different costumes, which interspersed, which lived there and which were in some way evidenced by written and/or material vestiges.

This was not a homogenous group, both for the population that had already lodged there and for the one that came later, there should existed a great variety of ideas about their status and how they should lead their lives.

Materials on Roman and Briton have already been found epigraphically on altars, tombstones and burials. However, this work will compare these first sources with the work of Tacitus, Annals, since this author always seems to place women with pejorative characteristics, very different from the loving and amorous words given to them in these places of death.
\end{abstract}

\title{
Keywords
}

Romans; Britons; women. 


\title{
Os estudos sobre as mulheres do mundo antigo
}

A reconstituição do passado é fundamentalmente localizada dentro do contexto do presente, assim como as políticas e os assuntos sociais do presente impactam sobre a reconstrução das sociedades (Shanks \& Tilley, 1992; Revell, 2016: 5) de tempos antigos.

\begin{abstract}
Inspirados por algumas propostas de Lowenthal (1985), acreditamos que o passado é fundamental para conhecermos nosso lugar hoje. Não estamos afirmando, com isso, que há uma linha direta entre passado romano e nosso cotidiano hoje no Brasil (Garraffoni e Funari, 2012), como se fôssemos herdeiros únicos e diretos de suas conquistas, ou que somos nostálgicos de algum momento da História, mas, ao contrário, nosso interesse pelo passado está em perceber sua multiplicidade, como possui diferentes papéis nas culturas, como é moldado - enfim, como o passado é construído e narrado (Funari \& Garrafoni, 2012: 11).
\end{abstract}

A segregação feminina atual faz com que haja a necessidade de estudos que demonstrem que ela também existia em outros tempos, uma vez que, de acordo com Revell (2016), em um passado não tão distante as elites governantes se moldaram em políticas elitistas greco-romanas, utilizando evidências textuais e materiais para justificarem sua posição de poder (Revell, 2016: 5).

Os estudos de gênero voltados à Antiguidade, conforme Marilyn Skinner (1993), ainda são muito conservadores, hierárquicos e patriarcais (Skinner, 1993; Funari, 1995: 179). Esse conservadorismo costuma se apoiar em leituras empiristas de fontes textuais, a partir de um senso comum. Funari (1995) sugere que se deve evitar esse tipo de abordagem, pois "apenas uma análise crítica permite compreender o 'masculino' e o 'feminino' como construções sociais que variam em termos de classe social, gênero e etnicidade, em diferentes períodos históricos e em diferentes sociedades" (Morgan, 1993: 194; Funari, 1995: 180).

As mulheres começaram a aparecer nos estudos clássicos depois que Finley, em 1965, publicou o artigo The Silent Women of Ancient Rome, argumentando que as fontes para o estudo das mulheres, nessa área, eram escassas e que, consequentemente, não se poderia propor uma imagem fiel delas. Mesmo assim, a quantidade de artigos sobre o assunto aumentou, pois foram encontradas novas maneiras de estudá-las. Portanto, desenvolveram-se condições para interpretar melhor as fontes e vários tipos de estudos expandidos poderiam englobar as mulheres, como, por exemplo, o estudo da família romana, que mostra como era o relacionamento do homem com a esposa, seus serviços domésticos e a inclusão do patronato, que acabou por envolver a mulher na vida econômica e social. Além destas, inclui-se a temática do profissionalismo, 
encontrada nos trabalhos e textos legais. As representações, especialmente na arte, na literatura e nas inscrições funerárias, também revelaram relações pessoais, da mãe com o pai e com as crianças. A Antropologia e a Demografia, por fim, ajudaram nos estudos sobre saúde e doenças, e o interesse em temas como a sexualidade e o erotismo também encorajaram os estudiosos a observarem o mundo romano com outros olhos (Rawson, 2006: 324).

$\mathrm{Na}$ década de 1990, uma série de trabalhos contextuais emergiu, colocando em prática as teorias de gênero e funcionando como ponto de partida para as críticas ao androcentrismo. Entretanto, algumas destas abordagens ficaram trancadas na linguagem da Segunda Onda Feminista e na 'descoberta das mulheres', com temas ligados à vestimenta e ao estilo de cabelo feminino, ignorando, assim, a complexidade do sexo, a sexualidade, a idade, o status, a etnicidade e outras possibilidades (Meskell, 1999; Bélo, 2014: 28-29).

Seguindo a Terceira Onda Feminista, começaram os estudos de gênero voltados para a idade, orientação sexual e etnicidade, tendo em vista que a identidade de gênero deveria ter sido concebida como algo complexo, classificado por uma rede de significados, variando de indivíduo para indivíduo ao longo do tempo, juntando-se a outras redes de práticas simbólicas localizadas nos conceitos de classe e raça. Definiu-se, assim, que a exploração feminina varia de acordo com a classe social, a raça e a divisão étnica em que ela está inserida (Meskell, 1999; Bélo, 2014: 29).

Eleonor Scott (1995), arqueóloga britânica, tem demonstrado como o estudo sobre as mulheres ainda vem sendo suprimido da academia. Em primeiro lugar, acerca da própria exclusão, a estudiosa menciona que as mulheres são completamente ignoradas devido às narrativas do mundo romano, que foram concentradas em atividades em que os homens eram dominantes, assim como a atividade política em Roma e nas províncias; em segundo lugar, a autora menciona haver uma pseudoinclusão, ou seja, as mulheres são incluídas, no entanto somente aparecem quando elas são anômalas às normas masculinas; e, por fim, ela defende a existência de uma alienação, a partir da qual a mulher somente é considerada em relação ao homem ou quando elas ameaçam o ponto de vista masculino no que diz respeito ao 'correto' comportamento delas (Scott, 1995: 176 9; Revell, 2016: 2).

Revell (2016) salienta que esses tipos de trabalhos não devem ser minimizados, isto é, não significa que eles não trazem contribuições, mas que suas interpretações da organização social do mundo romano são problemáticas em relação à categorização do(a) indivíduo(a). Essa 
dificuldade acontece de acordo com as próprias fontes romanas, as quais foram usadas para construir hierarquias sobre um discurso idealizado, em vez de providenciarem uma narrativa verdadeira, que mostrasse a vida das crianças, das mulheres ou dos escravos. Como a cultura material, essas fontes são partes dos significados pelos quais os romanos definiam suas 'minorias' (Revell, 2016: 3).

Neste estudo, fundamentou-se uma abordagem holística para a análise de relações de gênero (Funari, 1995), que se baseou em fontes textuais e materiais, seguindo o fato de que os estudos clássicos têm por natureza uma abordagem interdisciplinar, sendo, por essa razão, abertos a um estudo multicultural e pluralista de temas, como as mulheres e as relações de gênero (Rabinowtz, 1993, p. 16; Funari, 1995: 181).

Contudo, a proposta deste trabalho foi refletir sobre a mulher na sociedade antiga, com um critério que partiu da análise que relaciona a sociedade, os indivíduos e as relações. Este texto focou, então, nas mulheres da Britannia, romanas e bretãs, que compuseram diferentes costumes, que se entremearam, que ali viveram e que foram, de alguma forma, evidenciadas por vestígios escritos e/ou materiais.

\section{As fontes textuais e as mulheres}

Durante a leitura de alguns textos antigos, nota-se a depreciação da mulher por alguns autores. Um exemplo disso pode ser observado nas características dadas por Tácito e Dião Cássio na descrição que fizeram de Boudica, rainha bretã da tribo dos iceni, a qual liderou um exército contra o Império Romano, no século I d.C. Depois de recusar entregar suas terras aos romanos, Boudica foi açoitada e suas filhas, violentadas evento que ocorreu depois da morte de seu marido, Prasutago (Bélo, 2014: 43). Como consequência desse ato, ela, sua tribo e a tribo vizinha, os trinovantes, uniram-se para destruir os assentamentos romanos de Camulodunum, Londinium e Verulamium. Ela esteve no comando e foi caracterizada por esses autores como alguém que contrariou a concepção de mulher e de liderança que eles tinham (Bélo, 2014: 9).

Sendo assim, nas obras Anais e A vida de Agrícola, de Tácito, e História de Roma, de Dião Cássio, Boudica foi descrita de forma muito polêmica e caracterizada como uma mulher masculinizada, com a voz e as armas de um homem, agressiva e hostil, além de incapaz de liderar um exército, porém muito inteligente, se comparada com outras mulheres (Bélo, 2014: 9). A figura da guerreira, na posição de governante dos nativos, ia contra 
a questão de gênero aceita pelos romanos (Braund, 1996; Bélo, 2014: 45), pois suas mulheres tinham, em geral, um poder limitado dentro de uma sociedade governada por homens, embora pudessem possuir riquezas e serem influentes (Hingley \& Unwin, 2005; Bélo, 2014: 45).

De acordo com Johnson (2012), Tácito faz a seguinte comparação entre as mulheres que cita em sua obra: Cartimandua, outra rainha bretã, da tribo dos brigantes, aliada de Roma, foi considerada um símbolo da servidão romana e moralmente corrupta, como Messalina, primeira esposa de Cláudio acusada de adultério. ${ }^{2}$ No caso de Agripina, era muito marcante, extremamente política, de degeneração ética, vista como outra mulher imperial que simbolizou a decomposição de Roma. Tácito cita, que, da mesma forma que Cartimandua e Messalina, Agripina destruiu a unidade familiar e perturbou a liderança cívica, desestabilizando-a. O autor contrastou essa bretã com Boudica, a qual esteve ao lado de seu marido durante sua morte, consolidando remanescentes familiares e de sua tribo, e, ainda, lutou pela liberdade de seu povo (Johnson, 2012; Bélo, 2014: 10).

Cartimandua foi descrita nos Anais de Tácito como infiel ao marido. Segundo relata, ela teria entregado Carataco $^{3}$, líder de uma rebelião contra os romanos na ilha, no ano de 51 d.C. Tácito a retrata como traiçoeira, imoral e adúltera, enquanto Boudica, ao contrário, foi descrita como uma mulher devota e moral, porém equivocada (Hingley \& Unwin, 2005; Bélo, 2014: 44). Agripina participou do episódio de Carataco e, para Tácito, sua presença em assuntos de Estado, como este, não tinha precedentes constatados, principalmente quando ela reivindicou uma parceria no império que seus antepassados haviam criado (Barrett, 1996, p. 124). Na visão de Tácito, era uma novidade bastante estranha vê-la ultrapassar os padrões romanos, motivo pelo qual a caracterizou como uma parceira do império, a qual seus ancestrais tinham ganhado (Tacitus, Annals, 12.37).

Posteriormente, a percepção acerca dessas mulheres se alastrou. Até os dias de hoje, Boudica é a que mais atrai interesse, havendo, então, um maior número de trabalhos artísticos e escritos sobre ela, se comparada a Cartimandua. Essa justificativa está relacionada ao período do século

\footnotetext{
2 A lei de Augusto, lex Iulia de adulteriis, sempre definiu o adultério como um crime feminino. Contudo, os homens e a amante, que sempre era considerada culpada, poderiam levar algumas penalidades. A preservação da propriedade sexual da mulher era importante para a confiança do homem e para a legitimação de seus filhos, o que fazia parte de uma questão econômica e moral (Rawson, 2006: 328).

3 Carataco liderou uma rebelião contra o Império Romano anos antes de Boudica, rainha dos iceni (Johnson, 2012; Bélo, 2014: 10), mais especificamente em 51 d.C. (Hingley \& Unwin, 2005; Bélo, 2014: 44).
} 
XIX, quando esses trabalhos foram mais evidenciados, tendo em vista que a vida privada de Cartimandua não foi considerada um modelo para ser seguido (Allason-Jones, 2012: 469).

As mulheres romanas, diferentes das bretãs, não iam para o campo de batalha como o fez Boudica, mas, durante o período mais tardio da República e no início do Império, algumas delas começaram a ganhar mais independência, assim como Lívia, mulher de Augusto, que foi o grande exemplo. Ela difundiu uma tendência de que as mulheres de família imperial poderiam desfrutar de considerável influência por meio de um representante. Contudo, durante o período em que Tácito e Dião Cássio escreveram suas obras, algumas dessas poderosas mulheres da realeza já estavam notoriamente mais bem consentidas no meio político, principalmente devido a atividade de patronas, tais como as mulheres de Cláudio, Messalina, que foi executada, e Agripina, mãe de Nero, admirada e temida, além da esposa de Augusto, Lívia (Aldhouse-Green, 2006; Bélo, 2014: 9). Entretanto, as mulheres eram sempre sujeitas a certo grau de limitação em relação à capacidade de serem independentes. A autoridade de agir era obtida pelo pai, marido ou guardião (tutor). Até o período de Augusto, as únicas exceções eram as virgens vestais (Gardner, 1990, p. 5).

Segundo Fischler (1994), que foi diretora e supervisora da Society for the Promotion of Roman Studies, as mulheres imperiais do período JúlioClaudiano eram geralmente caracterizadas como transgressivas e violadoras dos seus papéis na sociedade. $\mathrm{O}$ segundo século do período Júlio-Claudiano foi tomado como uma aberração na história de Roma, pois nesse contexto imperadores violaram os privilégios e ameaçaram as vidas de senadores ou outras figuras de liderança. A estudiosa menciona que esses pontos representam uma característica comum para os autores dessa época, principalmente por ela se constituir como um momento de transição (Fischler, 1994: 120).

Outro fato que deve ser considerado refere-se à tradição literária, que sempre teve um interesse particular ao ser construída, sugerindo a necessidade de se comentar sobre essas mulheres, que, diante dos olhos romanos, saíram dos padrões. Tal fato revela os abusos que geralmente se cometiam na descrição das mulheres, bem como o que era particularmente censurável. A descrição dessas mulheres e seus comportamentos eram colocados para iluminar o caráter da "má" mulher imperial para o leitor e para mostrar o que esperavam de uma mulher da classe governante. Essas atitudes nos levam a indagar sobre o modo como as sociedades reagem diante de mulheres que possuem acesso à autoridade ou ao poder (Fischler, 1994: 121). 
Essas mulheres imperiais, como Lívia, Julia e Agripina, muitas vezes, tiveram que lidar com demandas de atividades que estavam além dos limites dos afazeres da casa para preencher as responsabilidades familiares, bem como entrar em contato com assuntos domésticos e públicos. Dessa forma, mulheres da elite romana começaram a conduzir os negócios da família e buscavam influenciar qualquer decisão tomada pelo dirigente da casa, o imperador. Sendo assim, a posição da mulher era fonte de tensão, revelando que nunca o poder do Estado poderia estar nas mãos delas (Fischler, 1994: 122). Essas atividades levaram essas mulheres a desenvolver o papel de patronas, ou de matresfamilias, tendo como função tomar conta não apenas da própria família estendida, mas também de outras famílias senatoriais, além de famílias de monarcas estrangeiros (Fischler, 1994: 123). O patronato, nesse sentido, ocorria quando um indivíduo provia uma doação vinda de suas riquezas em benefício à cidade ou a um pequeno grupo dentro dela (Meyers, 2012: 461). Em relação às mulheres, elas iniciaram supervisionando os negócios de família, possuindo escravos e protegendo escravos emancipados (Fischler, 1994: 124).

Ainda segundo Fischler (1994), as atividades que envolviam as mulheres imperiais se tornaram um padrão de categoria que era utilizado por esses autores para qualificar os imperadores, retratando, dessa forma, a qualidade e a natureza do governante "ruim". Fischler (1994) afirma que, para os romanos, os "bons" imperadores tinham mulheres e mães que eles podiam controlar e que nunca ultrapassariam os limites. Inerentemente, essas mulheres eram parte do império e vistas pelos homens da elite como ameaças a um "bom" governador. Por essa razão, escritores como Tácito e Dião Cássio utilizaram as "más" mulheres imperiais como sinônimo de Estado em desordem (Fischler, 1994: 127128).

\section{As mulheres da Britannia}

Ao se estudar as mulheres da Britannia, deve-se ter em mente que este não se tratava de um grupo homogêneo. Nesse local, antes da chegada dos romanos, habitavam tribos independentes (Allason-Jones, 2012: 467), com atividades, religiões, costumes e tradições distintas das dos invasores. Na verdade, tanto para a população que ali já tinha se alojado quanto para os que vieram depois, havia uma grande variedade de ideias a respeito do status das mulheres e do modo como elas deveriam conduzir suas vidas (Allason-Jones, 2012: 467). Dessa forma, não é tão simples identificar características, ou mesmo uma identidade, da mulher 
dessa região e período através das fontes escritas, as quais, muitas vezes, se contradizem em relação às fontes materiais.

O impacto dos diferentes modos de vida, no que se refere à cultura do "outro", pode ser visto em Tácito, que, ao descrever os germanos, por exemplo, salientou que eles não viviam em cidades, mas em assentamentos desorganizados, bem como que inexperientemente construíam suas casas (Tacitus Germania 16), classificando-os como não "civilizados". Outro exemplo foi dado por García (1997), em relação ao grego Estrabão, que, ao tratar dos cantabrianos da Península Ibérica, mencionou que aqueles que não tivessem cidade não eram considerados "civilizados", pois viviam como animais (García, 1997: 162). ${ }^{4}$ De acordo com Hingley (1997), a existência de construções de casas redondas pelos romanos, típica dos nativos, por exemplo, demonstrou a possibilidade de uma não resistência ou mesmo da não imposição de uma cultura sobre a outra (Hingley, 1997; Revell, 2016: 46). Tal fato pode ser demonstrado pela cultura material de Vindolanda (fig. 1), uma vez que os romanos começaram a incorporar esse tipo de edifício redondo nas suas próprias construções. Para Revell (2016), pode ter havido um processo de integração dos grupos, o que também pode ter levado a significativas transformações (Revell, 2016: 55). ${ }^{5}$

\footnotetext{
4 Desde o período de Heródoto a concepção grega do 'outro' foi articulada de acordo com o conceito de 'bárbaro'. Inicialmente, associado aos Persas, o termo 'bárbaro' conotava para Heródoto e outros gregos, uma inclinação à subserviência e tirania. Para os escritores romanos que, subsequentemente, se apropriaram do conceito em suas narrativas, acabaram dando uma ideologia política ao império. Dessa forma, o termo 'Barbarismo', para esses últimos, implicava uma condição inferior, assim como uma natureza inferior (McCoskey, 2005: 60 - 61; Saavedra, 1999: 60).

5 Essa questão implica no debate sobre o termo Romanização, conceito que foi criado no início do século XX, pelo inglês Francis Haverfield para explicar o crescimento do Império Romano. Ele foi um dos fundadores da Arqueologia romano-britânica, e elaborou o conceito de Romanização a partir de seus estudos e escavações em território britânico, junto com as ideias do alemão Mommsen (Funari \& Garraffoni, 2004: 11).

De acordo com Funari e Garraffoni (2004), Hingley e demais estudiosos que seguem uma perspectiva pós-colonial enfatizam que a ideia de Romanização era vinculada à visão inglesa imperialista. Para Hingley é impossível compreender o conceito de Romanização sem recorrer ao momento histórico que fora criado, ou seja, um período em que ingleses acreditavam que o progresso e a civilização só poderiam chegar sob liderança imperial, como se houvesse uma transposição de valores ingleses para o passado romano. Acreditava-se que os ingleses herdaram dos romanos, via descendência bretã, a missão de civilizar povos bárbaros no mundo (Funari \& Garraffoni, 2004: 11 - 12).

O termo Romanização estava vinculado ao conceito de aculturação, em que o prefixo "a" vem do latim $a d$, que indica um movimento de aproximação, e foi criado em 1880, por J. W. Powell, antropólogo americano, que via a aculturação como uma ação de mão
} 


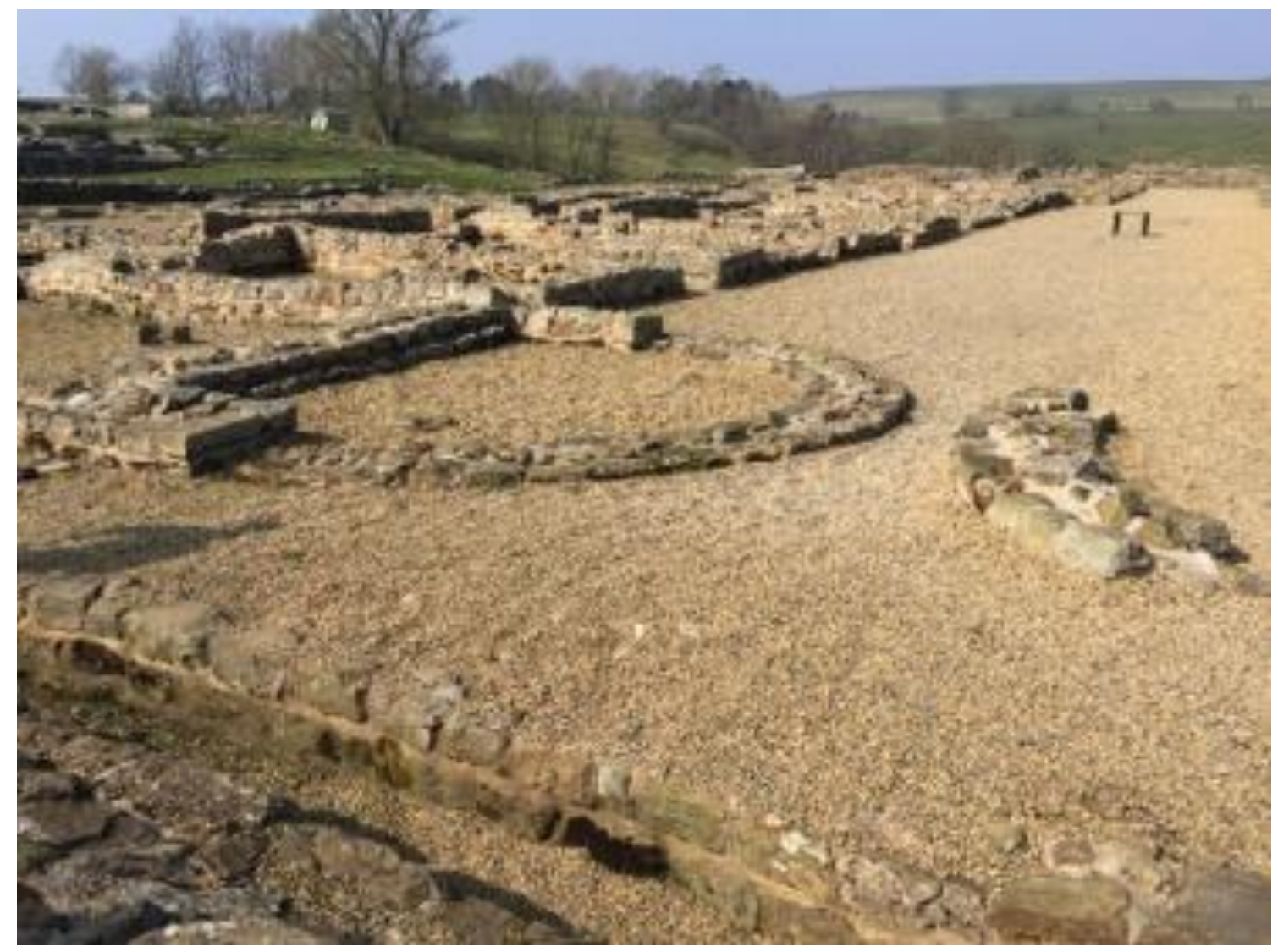

Figura 1. Sítio Vindolanda, norte da Inglaterra (Bélo, 2017).

Com a chegada dos romanos a Britannia, pode-se imaginar que surgiu ali uma variedade de reações em relação aos ideais sociais, havendo a possibilidade de qualquer pessoa rejeitar as normas, resultando, por exemplo, em revoltas dos nativos, como a de Carataco e a de Boudica. Entretanto, a rejeição somente pode ser compreendida dentro de um dado contexto do discurso da própria sociedade (Revell, 2016: 10), pois as ações das pessoas sujeitam-se à noção do que é apropriado para um aspecto em específico da identidade do grupo a que elas pertencem, de acordo com categorias, como o status social e a etnia. Além disso, a ideia de apropriação está configurada a partir da expectativa das normas

única (Coche, 1999), que diante de uma visão evolucionista, o mais forte sempre prevaleceria sobre o mais fraco, ou seja, era pensado que o colonizador subjugaria o colonizado. Apenas nos anos 50, que o francês Roger Bastide, discípulo de Franz Boas (geógrafo e antropólogo alemão, que atuava nos EUA), dedicou-se a trabalhos sobre a cultura afro-brasileira e introduziu na França pesquisas sobre a aculturação. Em sua análise levou em conta tanto o grupo que dá, quanto o grupo que recebe, pois para o estudioso não havia uma cultura unicamente "doadora", nem uma cultura unicamente "receptora" propriamente dita. A aculturação não se produz jamais em mão única. Toda cultura é um processo permanente de construção (Coche, 1999).

Diante desse debate sugere-se não se utilizar o termo aculturação e sim outros, como interação, utilizado pelo arqueólogo Ian Hodder (2009), ou contato. 
sociais (Revell, 2016: 10) pertencentes ao grupo no qual as pessoas estão acostumadas a viver.

Um exemplo da heterogeneidade cultural nas relações humanas existente na Britannia é o jazigo de Julia Velva (RIB 688) e família, feito em pedra, que foi encontrado em 1922, durante a construção de uma nova estrada a sudeste de Mount, em direção a South Bank, York, e que hoje se encontra exposto no museu de Yorkshire (fig. 2). ${ }^{6}$ Tal jazigo demonstra que Aurelio Mercuriale refere-se a si mesmo no epitáfio como herdeiro de Julia Velva e que ele construiu esse túmulo para ele e sua família. A falta de um nome em comum entre ela e seu herdeiro sugere que ela não era nem sua filha ou sua irmã, mas parte da família. Ela poderia ser sua sogra, mas os termos "viveu como a mais obediente" eram mais comumente utilizados para esposas ou amantes livres. Algumas evidências epigráficas de Roma mostram que mulheres livres poderiam fazer parte da família e ser enterradas juntas (Allason-Jones, 2005: 12-13), porém, dificilmente, deixaria uma herança para um homem. De acordo com as informações contidas no site, Roman Inscription of Britain, Velva não era um nome latim, e, sim, celta, sugerindo que Julia poderia se tratar de uma mulher livre, que não precisava seguir as leis de Roma de forma rigorosa. ${ }^{7}$

Outro exemplo de união entre romanos e nativas está no sepultamento de Regina, encontrado em South Shields, datado de II d.C. (fig. 3), que, além das inscrições, apresenta sua imagem com roupas, joias e mobília, caracterizando um verdadeiro altar. A inscrição diz que ela era uma nativa da tribo dos catuvellauni, que morreu aos trinta anos (RIB 1065), e era uma mulher livre, esposa de Barates, de Palmira (Allason-Jones, 2012: 470).

O altar de Regina está dividido em quatro fragmentos e emoldurado em duas pilastras nas quais a falecida fica sentada em uma cadeira de vime voltada para frente. Ela veste um manto com mangas longas sobre uma túnica, o qual chega até os pés. Em volta de seu pescoço, há um colar e pulseiras em seus punhos. Em seu colo, ela possui uma roca e um fuso. Além disso, do seu lado esquerdo encontra-se um cesto de trabalho, com novelos de lã, e com sua mão direita ela segura um porta-joias aberto. Ela possui uma grande auréola em volta de sua cabeça, mas seu rosto está

\footnotetext{
${ }^{6}$ Disponível em https://romaninscriptionsofbritain.org/inscriptions/688, acessado em 11/04/2017.

${ }^{7}$ Disponível em https:// romaninscriptionsofbritain.org/inscriptions/688, acessado em 11/04/2017.
} 
cortado. $^{8}$

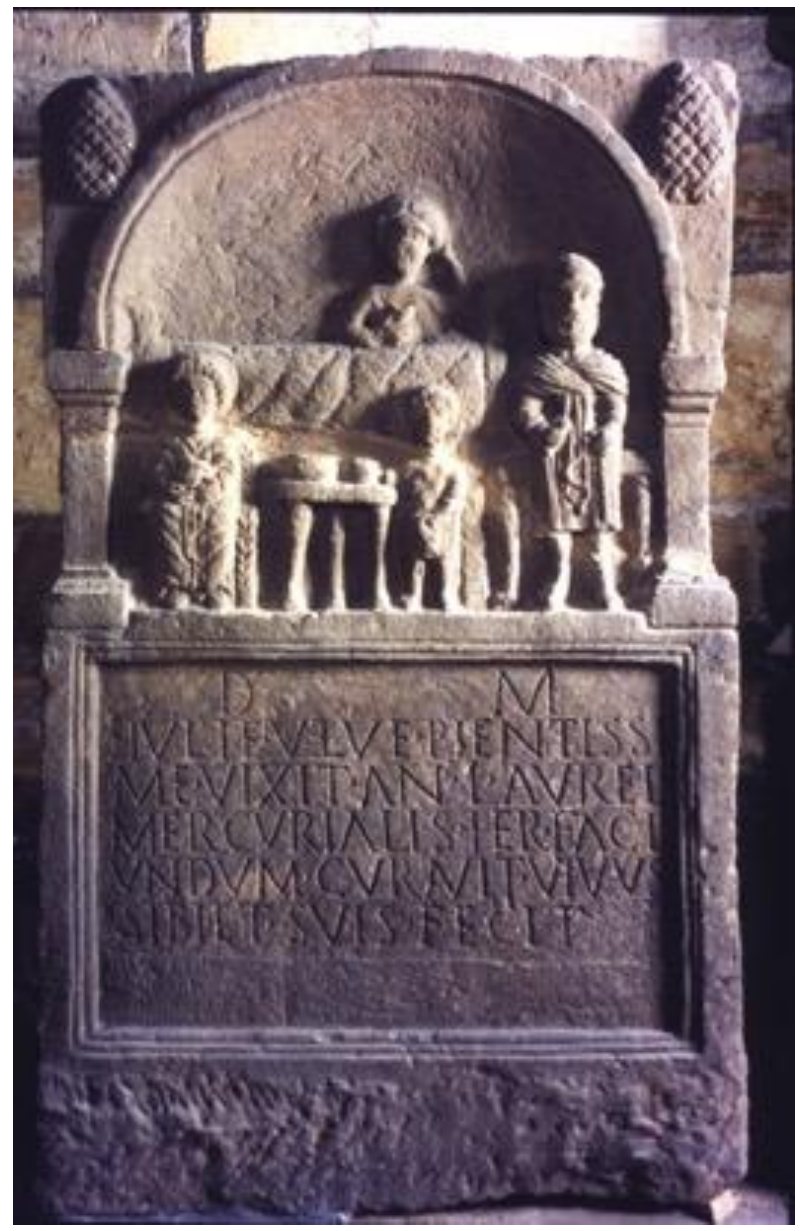

Figura 2. Jazigo familiar de Aurelius Mercurialis com Julia Velva. Image courtesy of York Museums Trust :: http://yorkmuseumstrust.org.uk/ :: CC BY-SA 4.0

Epitáfio:

$\mathrm{D}$ (is) M(anibus)

Iulie Velve pientissi-

me vixit an(nos) L Aurel(ius)

Mercurialis he(es) faci-

undum curavit vivus

sibi et suis fecit ${ }^{9}$

Tradução:

Aos Deuses Manes e a Julia Velva: ela viveu como a mais obediente durante 50 anos. Aurelio Mercuriale, seu herdeiro, construiu esse monumento e durante sua vida fez isso para si e para sua família ${ }^{10}$.

8 Disponível em http://romaninscriptionsofbritain.org/inscriptions/1065, acessado em 02/11/2015.

${ }_{9}^{9}$ Disponível em https:/ / romaninscriptionsofbritain.org/inscriptions/688, acessado em 11/04/2017.

10 Tradução nossa, inglês - português, 2017. 


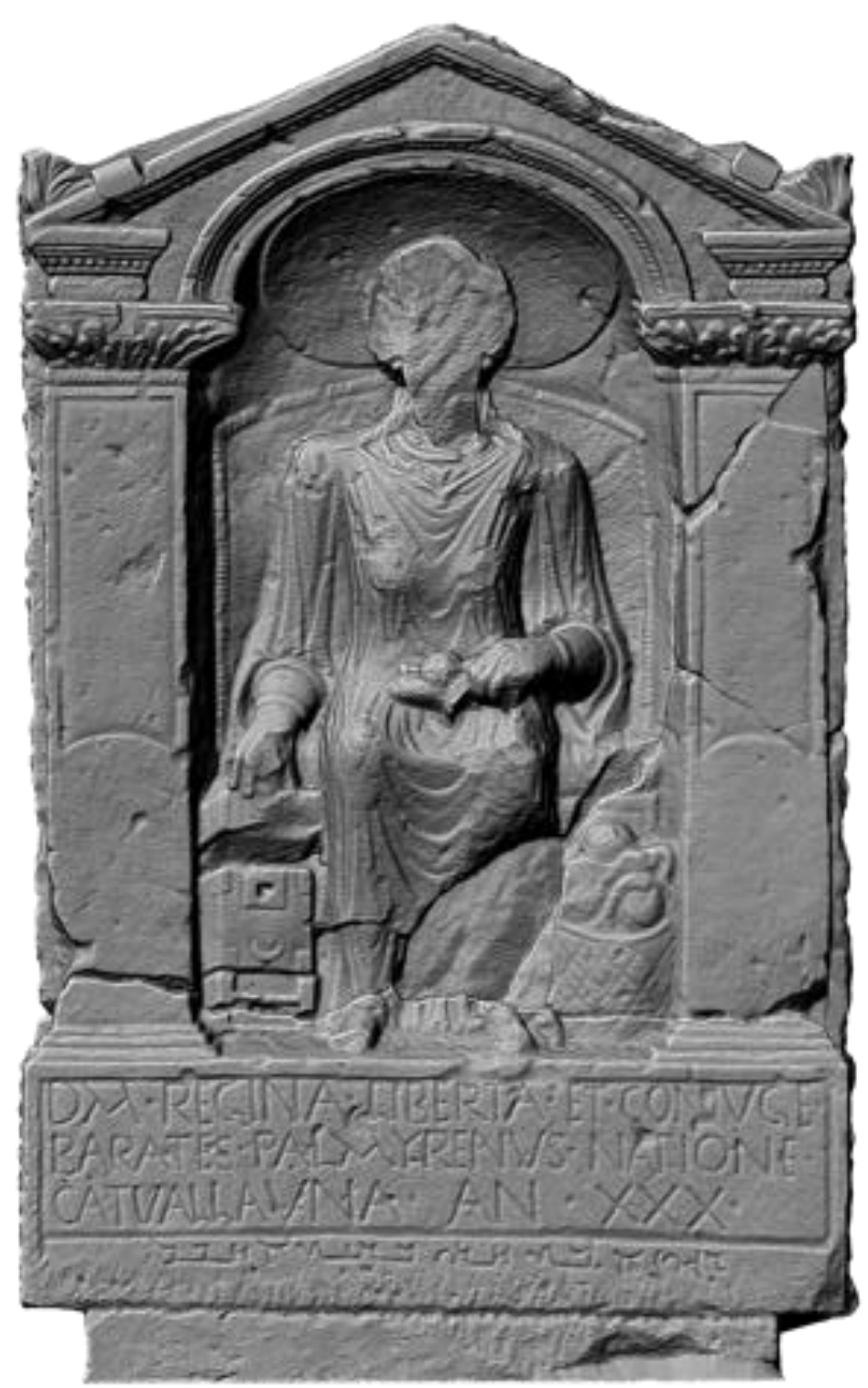

Figura 3. Altar de Regina, encontrado em South Shields, datado do século II d.C. (c) Newcastle University all rights reserved.

Epitáfio:

$\mathrm{D}$ (is) M(anibus) Regina liberta et coniuge

Barates Palmyrenus natione

Catvallauna an(norum) XXX ${ }^{11}$

Tradução:

Barates de Palmira (construiu este monumento), em dedicação aos Deuses Manes, para a liberta Regina, sua esposa, da nação catuvelauna, com trinta anos de idade ${ }^{12}$.

De acordo com Allason-Jones (2005), Regina poderia ter sido, primeiramente, uma escrava, com um aparente comércio doméstico em

11 Disponível em http://romaninscriptionsofbritain.org/inscriptions/1065, acessado em 02/11/2015.

12 Tradução P. P. A. Funari, 2017, que entende, com RIB 1065, que Regina liberta está no ablativo, no lugar do usual dativo. 
atividade. Pelo fato de as inscrições demonstrarem que era uma mulher livre, pressupõe-se que ela pode ter sido escrava por um determinado tempo. No final do século II d.C., era difícil compreender como um membro de uma tribo bretã e nascida livre poderia ter se tornado uma escrava. Allason-Jones (2005) sugere que o único modo de isso ter acontecido seria a venda dela pelos pais. Acrescenta-se que essa prática foi banida por Roma até 313 d.C., mas, em face de evidências em Noricum e em outras partes do Império, parece que essa atividade acontecida em todas as regiões entre os séculos II e III d.C. (Allason-Jones, 2005: 14). Essa hipótese sobre Regina também pode ser empregada no caso de Julia Velva.

As duas nativas, tanto Regina quanto Julia Velva, parecem ter vivido uma experiência discrepante, que foi expandida por causa de uma identidade oposta. Deve-se ter em mente que múltiplos fatores podem ser reconhecidos como aqueles que formam as experiências de vida de uma pessoa, dos quais, alguns podem ter sido impactantes para a identidade delas, como, por exemplo, a disparidade em relação ao status, localização, religião, origem, língua, gênero, idade, etc (Mattingly, 2004; Revell, 2016: 14). Outra explicação se relaciona ao fato de que Regina pode ter sido vítima do impacto do imperialismo romano e das relações de poder, que podem ser caracterizados como uma transformação que não foi neutra, mas uma estratégia de controle pelas autoridades imperiais (Revell, 2016: 56). O casamento entre romanos e nativas poderia ser potencialmente um processo de remoção da identidade nativa. Embora os nativos possam ter permanecido, as relações dentro desse grupo e, potencialmente, entre os grupos podem ter sido refeitas dentro de uma ideologia romana, e essa assimilação pode ter sido variável, assim como poderia ter sido incentivada pelo mecanismo do esquecimento. Allanson-Jones (2005) sugere, no que concerne à identidade, que muitas dessas mulheres poderiam ter se sentido deslocadas, confusas e psicologicamente doentes e que o suicídio poderia ter acontecido (Allanson-Jones, 2005: 76).

Em várias dessas lápides, evidencia-se o carinho que os maridos tinham por suas esposas, assim como inscrições que mencionavam expressões amorosas e de ternura, como, por exemplo: "amada esposa" (RIB 621), "muito amada esposa" (RIB 959) e "a mais devota das esposas" (RIB 17) (Allason-Jones, 2004: 280). Nessa perspectiva, pode-se concluir que, ao que parece, essa cultura material demonstra, além de afeto, algo bem diferente da forma como as fontes escritas caracterizaram as mulheres da Antiguidade, conforme foi evidenciado em obras de escritores antigos na primeira parte deste trabalho. 
Um exemplo é o jazigo de Aurelia Aureliana (RIB 959) (fig. 4), feito de arenito lustroso, encontrado em 1819, no cemitério romano em Gallows Hill, sul de Carlisle (Luguvalium), Inglaterra, encontrado quando fizeram um corte para a estrada principal. O jazigo foi transferido para o Museu de Antiguidades de Newcastle. Hoje em dia ele pertence ao Great North Museum, de Hancock. ${ }^{13}$

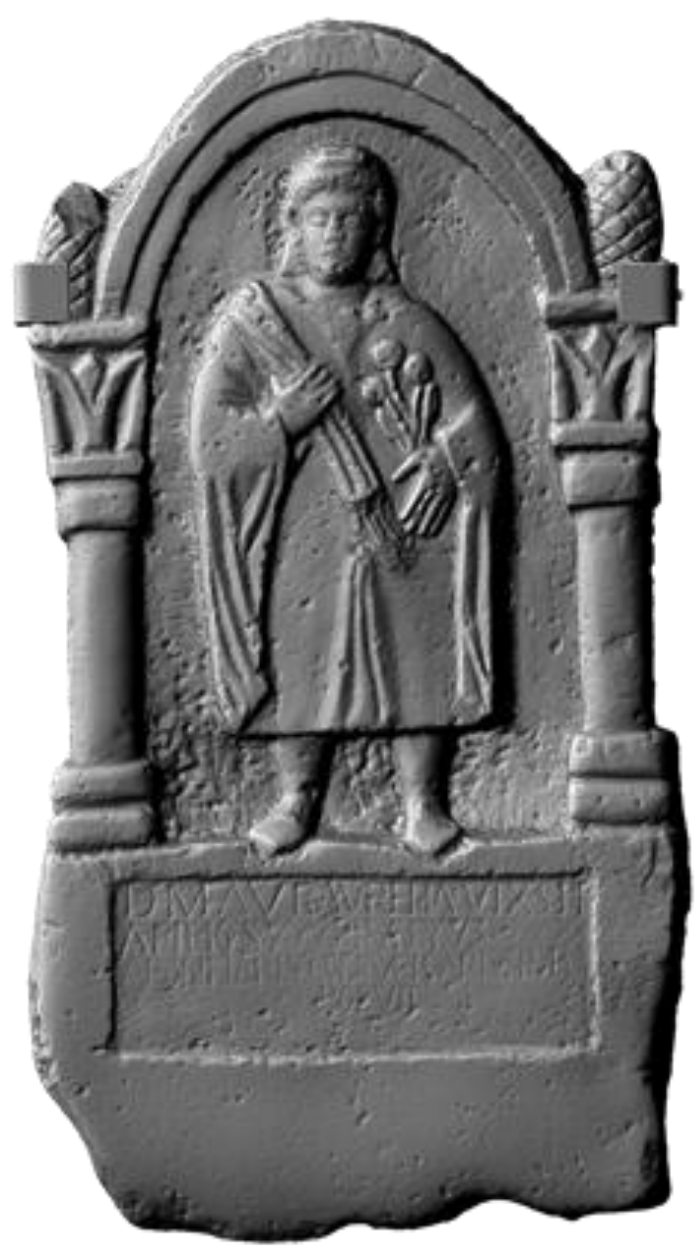

Figura 4 - Jazigo de Aurelia Aureliana. (C) Newcastle University all rights reserved Epitáfio:

D(is) M(anibus) Aur(elia) Aurelia(na) vixsit annos XXXXI Ulpius

Apolinaris coniugi carissime

posuit ${ }^{14}$

Tradução:

Aos Deuses Manes, Aurelia Aureliana, viveu 41 anos. Ulpio Apolinari construiu esse monumento para sua muito amada esposa ${ }^{15}$.

${ }^{13}$ Disponível em: https://romaninscriptionsofbritain.org/inscriptions/959, acessado em 04/07/2017.

${ }_{14}$ Disponível em: https://romaninscriptionsofbritain.org/inscriptions/959, acessado em 04/07/2017.

15 Tradução nossa, inglês - português, 2017. 
Os romanos, ao enterrarem seus parentes, homenagearem benfeitores, fazerem votos junto aos seus deuses, adorarem seus imperadores ou inaugurarem prédios, geralmente, faziam inscrições para serem preservadas permanentemente. Entretanto, ao descreverem suas mulheres mortas, por exemplo, utilizaram-se de fórmulas altamente estereotipadas e padronizadas por séculos (Riess, 2012, p. 491), o que dificulta o acesso, na atualidade, em se conhecer as mulheres daquela época de forma mais aprofundada.

\section{Conclusão}

De acordo com Susan Fischler (1994), as lápides foram projetadas para comemorar a família desolada, mostrando as virtudes tradicionais da falecida, com o objetivo de descrever a mulher morta nos mais altos padrões esperados pela comunidade social, exemplificando-a como a matrona romana ideal, que é conhecida por sua beleza, fertilidade e fidelidade a seu marido, bem como pela sua capacidade de dirigir o lar (Fischler, 1994: 117). Sendo assim, as relações de poder, que sustentam um significado de identidade, podem demonstrar através da cultura material o resultado do produto de um processo, que envolve certos grupos que foram pouco visíveis (Revell, 2016: 17) em sua totalidade, assim como as mulheres.

Em torno de todos esses aspectos Riess (2012) levanta a ideia que o marido cuidadosamente balanceava o jogo de gênero com a invocação dos tradicionais estereótipos de valores, sendo que as inscrições não descreviam realmente quem a pessoa era, mas um tipo, que foi enumerado com valor coletivo e que reproduziu um código de normas. $\mathrm{O}$ intuito era que o texto honorário e material de ostentação provocasse a amostragem das virtudes da morta para deixar sua memória viva, o que acabava por ser um benefício para o marido que ainda permanecia vivo (Riess, 2012: 497). A linguagem latina da epigrafia foi gerada e trabalhada como instrumento de manutenção da dominância masculina sobre a feminina, demonstrando, dessa forma, que as inscrições confirmam uma dimensão da variedade histórica de formação do gênero, o qual é uma construção social e transmitido para uma comunidade através de certos veículos de significados ou símbolos. As inscrições serviam como representações de harmonia, no sentido de idealizarem os relacionamentos entre os indivíduos e entre as classes sociais como ditos 'apropriados', demonstrando valores, normas, comportamentos, com longa duração, como um meio constante e firme (Riess, 2012,: 499 - 500) 
Ao tratarem das mulheres de povos nativos, os autores antigos o fizeram com exceção, especialmente, quando as informações chocavam com o conceito tradicional desses escritores, assim como a posição das mulheres na família e sociedade, tomando esses modelos como protótipos para exaltarem as virtudes romanas (Franco, 1999: 57). Desse modo, os trabalhos de Tácito e Dião Cássio, por exemplo, devem ser tomados a partir de uma reflexão sobre um fenômeno complexo, que envolve uma consideração no que concerne à diversidade de identidade, cultura e gênero vista de uma perspectiva estrangeira em relação ao 'outro' e que abarca o debate sobre o contato entre romanos(as) e nativos(as) durante $o$ Império Romano.

\section{Fontes antigas}

CASSIUS DIO. 1925. Roman History. English translation by E. Cary. London: G. B. Putman.

STRABO. 1923. Geography. English translation by H. L. Jones. Published in volume II of the Loab Classical Library edition. Cambridge, Massachusetts: Harvard University Press.

TACITUS, P. C. 1914. Agricola. Translated by M. Hutton, revised by W. Peterson. London: William Hinemann LTC; Cambrigde, Massachusetts: Harvard University Press.

1916. The Germania. Introduction and notes by D. R. Stuart. New York: The Macmillan Company.

1968. The Annals of Imperial Rome. Translation by M. Grant. Great Britain: Penguin Classics.

\section{Referências bibliográficas}

ALDHOUSE-GREEN, M. Boudica Britannia. London: Pearson Longman, 2006.

ALLASON-JONES, L. The Family in Roman Britain. In: Todd, M. (Ed.). A companion to Roman Britain. Oxford: Blackwell Publishing, 2004.

Women in Roman Britain. York: Council for British Archaeology, 2005. 
Women in Roman Britain. In: James, L. S. \& Dillon, S. (Ed.). A companion to women in the Ancient world. Oxford: Blackwell Publishing.

BARRETT, A. A. Agrippina: sex, power, and politics in the early empire. Yale, London: Yale University Press, New Haven, 1996.

BELO, T. P. 2014. Boudica e as facetas femininas ao longo do tempo: nacionalismo, feminismo, memória e poder. Tese de doutoramento apresentada ao Programa de pós-graduação do Instituto de Filosofia e Ciências Humanas da Universidade Estadual de Campinas. Departamento de História, área de concentração em História Cultural.

BRAUND, D. Ruling Roman Britain: kings, queens, governors and emperors from Julius Caesarto Agricola, London, Routledge, 1996.

COCHE, D. 1999. A noção de cultura nas Ciências Sociais. Bauru: Edusc.

FINLEY, M. I. 1965. The silent women of the ancient world. Horizon 7, 57 - 64 (= M. I. Finley 1977) Aspects of Antiquity, 129 - 42. London).

FISCHLER, S. 1994. Social Stereotypes and Historical Analysis: the case of the imperial women at Rome. In: Women in Ancient Societies. New York: Routledge.

FRANCO, H., G. 1999. La imagen de la mulher "bárbara": a propósito de Estrabon, Tácito e Germania. In: Faventia, 21/1.

FUNARI, P. P. A. 1995. Romanas por elas mesmas. Cadernos pagu (5) 1995: pp. 179-200.

FUNARI, P. P. A. \& GARRAFONI, R. S. História Antiga na Sala de Aula. Campinas, IFCH/UNICAMP, Julho de 2004, Textos Didáticos s2004, n. 51, 90 pp., ISSN 1676-7055.

Historiografia: Salústio, Tito Lívio e Tácito. Capinas: Unicamp, 2016.

GARCIA, M., L. 1997. Las mujeres en la Gallaecia antigua. In: Gallaecia, 16, pp. $159-172$.

GARDNER, J. F. Women in roman law and society. London: Routledge, 1990.

GARRAFFONI, R. S. \& FUNARI, P. P. A. The uses of Roman heritage in Brazil. Heritage and society, 2012,. v. 5, pp. $53-76$. 
HINGLEY, R. Resistance and domination: social change in Roman Britain. In: D. Mattingly (ed.) Dialogues in Roman Imperialism: power, discourse and discrepant experience in the Roman empire. Portsmouth, R. I., Journal of Roman archaeology supplementary series, 1997, 23: 81 - 100.

HINGLEY, R. \& UNWIN, C. Boudica: Iron Age warrior queen. London: Hambledon Continuum, 2005.

HODDER, I. Symbols in action: ethnoarchaeological studies of material culture. Cambridge: Cambridge University Press, 2009.

JOHNSON, M. Boudicca. London: Bristol Classical Press, 2012.

LOWENTHAL, D. The past is a foreign country. Cambridge: Cambridge University Press, 1985.

MATTINGLY, D. Becoming Roman: expressing identity in a provincial setting. In: Journal of Roman Archaeology, 2004, 17, pp. 5 - 25.

MCCOSKEY, D., E. 2005. Gender at the crossroads of empire: locating women in Strabo's Geography. In: DANIELA DUECK, HUGH LINDSAY AND SARAH POTHECARY (Eds.). Strabo's cultural geography: The Making of a Kolossourgia. Cambridge: Cambridge University Press, pp. 56 - 72.

MESKELL, L. Archaeology of social life: age, sex, class et cetera in Acient Egypt. Oxford: Blackwell Publishers Inc, 1999.

MEYERS, R. 2012. James, S. L. \& Dillon, S. (eds.). Female portraiture and female patronage in the high imperial period. A companion to the women in the Ancient World. Malden, Oxford, Chichester: Blackwell Publishing.

MORGAN, D. Discovering Men. Londres: Routledge, 1993.

PINA-CABRAL, J. 1993. Tamed violence: genital symbolism in Portuguese popular culture. Man (NS), 28, 1, p. 118.

RABINOWITZ, N. S. Introduction. IN: Rabinowitz, N. S. e Richlin, A. (eds.). Feminist Theory and the Classics. Londres, Routledge, 1993; cf. RICHLIN, Amy: "Hijacking the Palladion: Feminists in Classics", Gender and History, 4,1, pp.70-83.

RAWSON, B. 2006. Finding roman women. In: Rosenstein, N. \& Marx, R. M. (eds.) A companion to the roman republic. Oxford: Blackwell Publiching, pp. $324-341$. 
REVELL, L. Ways of being roman: discourses of identity in the roman west. Oxford \& Philadelphia: Oxbow Books, 2016.

RIESS, W. Rari exempli femina: female virtues on Rome. In: James, S. L. \& Dillon, S. (orgs.). A companion on women in the Ancient World. Chichester: Wiley - Blackwell, 2012.

SAAVEDRA, T. Women as focalizers of barbarism in conquest texts. Echos du Monde Classique, 1999, n.s. 18: 59-77.

SCOTT, E. Women and gender relations in the Roman empire. In: P. Rush (ed.) Theoretical Roman Archaeology: second conference proceedings. Aldershot, Avebury, 1995. pp. $174-89$.

SHANKS, M.; TILLEY, C. Reconstructing Archaeology: theory and practice. $2^{\text {nd }}$ ed. London, Routledge, 1992.

SKINNER, M. Woman and Language, in Archaic Greece, or Why is Sappho a Woman? In: Rabinowitz, N. S. e Richlin, A. (eds.). Feminist Theory and the Classics. Londres, Routledge, 1993. 